\title{
Nitrogen status and heat-stress-dependent differential expression of the cpn60 chaperonin gene influences thermotolerance in the cyanobacterium Anabaena
}

Correspondence

Shree Kumar Apte

aptesk@barc.gov.in

Received 27 June 2007

Revised 6 September 2007

Accepted 4 October 2007

\author{
Hema Rajaram and Shree Kumar Apte
}

Molecular Biology Division, Bhabha Atomic Research Centre, Trombay, Mumbai 400 085, India

\section{INTRODUCTION}

The heat-shock response (HSR) involves de novo synthesis of heat-shock proteins (Hsps) comprising several chaperones (Hsp70, Hsp60) and proteases (Lon, Clp). HSR is a universal stress response that living organisms use to restore homeostasis during short-term temperature up-shifts and other environmental stresses (Morimoto et al., 1994; Yura et al., 2000). Although studied in great detail in several bacteria and higher organisms, the HSR is not so well understood in nitrogen-fixing cyanobacteria. Most bacteria possess a single bicistronic groESL operon harbouring the groES and groEL genes encoding a 10 and a $60 \mathrm{kDa}$ chaperonin, respectively (Yura et al., 2000). Occurrence of additional $h s p 60$ genes in Streptomyces species (Guglielmi et al., 1991), Mycobacterium tuberculosis and M. leprae (Rinke de Wit et al., 1992), and of multiple groEL genes in rhizobia (Rusanganwa \& Gupta, 1993) and Bradyrhizobium japonicum (Fischer et al., 1993) has also been reported. All cyanobacteria whose genomes have been completely sequenced exhibit two distinct $h s p 60$ genes, a groEL gene as part of the groESL operon and a

Abbreviations: chl, chlorophyll; Hsp, heat-shock proteins; HSR, heatshock response; $\mathrm{MV}_{\mathrm{r}}-\mathrm{NR}$, reduced methyl viologen-dependent nitrate reductase.

The GenBank/EMBL/DDBJ accession number for the sequence of the insert from construct pHR302 is AY328922. solitary cpn60 gene (Chitnis \& Nelson, 1991; Lehel et al., 1993; www.kazusa.or.jp/cyano).

Earlier work from our laboratory showed that (a) the two Hsp60 protein-encoding genes are expressed abundantly in the nitrogen-fixing cyanobacterium, Anabaena sp. strain L31 (hereafter referred to as Anabaena L-31) during exposure to heat and other environmental stresses (Apte et al., 1998; Bhagwat \& Apte, 1989), and (b) nitrogen-fixing Anabaena L-31 cultures recover from prolonged exposure to continuous heat stress as a consequence of continuous synthesis, greater stability and accumulation of the two Hsp60 proteins during heat stress (Rajaram \& Apte, 2003). In this study, we have cloned the cpn60 gene from Anabaena L-31 and compared its expression with that of groEL (Rajaram et al., 2001; Rajaram \& Apte, 2003) in response to nitrogen status and heat stress. Our results demonstrate that loss of Cpn60 during heat stress in nitrate-supplemented cultures of Anabaena correlates with the inactivation of the photosynthetic machinery and nitrate reduction, while Cpn60 overexpression enhances the thermal stability of these vital metabolic processes.

\section{METHODS}

Organism and growth conditions. Anabaena L-31 (Thomas, 1970) and Anabaena sp. strain PCC7120 (hereafter referred to as Anabaena 
7120) were grown in BG-11 liquid medium, pH 7.0 (Castenholz, 1988 ) with (BG-11, $\mathrm{N}^{+}$) or without (BG-11, $\mathrm{N}^{-}$) combined nitrogen (17 mM $\mathrm{NaNO}_{3}$, or $3 \mathrm{mM} \mathrm{NH} \mathrm{NH}_{4} \mathrm{Cl}$ with $5 \mathrm{mM} \mathrm{MOPS}$ ) under continuous illumination $\left(30 \mu \mathrm{E} \mathrm{m}^{-2} \mathrm{~s}^{-1}\right)$ and aeration $\left(31 \mathrm{~min}^{-1}\right)$ at $27^{\circ} \mathrm{C}$. The transgenic Anabaena 7120 strain AnFPNcpn was maintained in BG-11, $\mathrm{N}^{+}$supplemented with $25 \mu \mathrm{g}$ neomycin $\mathrm{ml}^{-1}$ (hereafter referred to as $\mathrm{BG}-11, \mathrm{~N}^{+} \mathrm{NeO}_{25}$ ). Heat stress involved exposure to $42{ }^{\circ} \mathrm{C}$, other growth conditions being identical. For thermotolerance and recovery experiments, the heat-stressed cultures were inoculated into fresh, BG-11 medium at $1 \mu \mathrm{g}$ chlorophyll (chl) $a$ $\mathrm{ml}^{-1}$. Growth was measured as chl $a$ content in methanolic extracts as described by Mackinney (1941).

Measurement of photosynthetic, nitrate reductase and glutamine synthetase activities. Light-dependent photosynthetic oxygen evolution was measured using the Oxygen Monitoring System (OxyLab, Hansatech Instruments). Oxygen evolution measurement involved three alternating cycles of light and dark for 5 min duration each and calculation of the average rate. Cellular nitrate reductase activity was estimated as extracellular nitrite released either in light as natural reductant (L-NR) (Hageman \& Hucklesby, 1971) or with reduced methyl viologen $\left(\mathrm{MV}_{\mathrm{r}}-\mathrm{NR}\right)$ (Herrero et al., 1981). The results from both assays were similar. Glutamine synthetase activity was assayed by the transferase assay described by Martin et al. (1997).

Two-dimensional IEF/SDS-PAGE. The cell-free protein extract was prepared by repeated freezing-thawing of the cells resuspended in $10 \mathrm{mM}$ Tris buffer, $\mathrm{pH} 8.0$, followed by centrifugation $(10000 \mathrm{~g}$, $5 \mathrm{~min}$ ) to collect the supernatant. Proteins were subjected to isoelectric focussing (IEF) using ampholines (Amersham Biosciences) of two $\mathrm{pH}$ ranges, $3-10$ and 3.5-5, mixed in a $2: 1$ ratio in tube gels followed by resolution using $10 \%$ SDS-PAGE (Bhagwat \& Apte, 1989).

Genomic DNA isolation, PCR amplification and electrophoresis of DNA fragments. Anabaena genomic DNA was isolated as described previously (Apte \& Haselkorn, 1990). PCR amplification of genomic DNA (100 ng) was carried out using Taq DNA Polymerase (Roche Biochemicals). DNA samples were electrophoretically resolved on $0.7 \%$ agarose gels in TBE (Tris-Borate-EDTA) at $80 \mathrm{~V}$ for $2 \mathrm{~h}$.

Cloning of Anabaena L-31 cpn60 gene and groESL operon. The $1.7 \mathrm{~kb}$ cpn60 gene was amplified from Anabaena L-31 chromosomal DNA using the cpn60F2 and cpn60R1 primers (Table 1), designed on the basis of the genome sequence of Anabaena 7120. The PCR product was end-filled with dNTPs and Klenow enzyme and ligated to EcoRV-digested plasmid vector, pBluescript SKII. The insert from

Table 1. List of primers used for PCR amplification

\begin{tabular}{|c|c|}
\hline Primer & Sequence $\left(5^{\prime}-3^{\prime}\right)^{*}$ \\
\hline cpn60F2 & GTATCCTACATGAGCATCAAG \\
\hline cpn60R1 & ACGATCGCTTCGGTGGTG \\
\hline cpn60OEFwd & GCCATATGGCAAAAATTATTTCA (NdeI) \\
\hline cpn60OERev & GCCTCGAGGAAC ATACCCATACCACC $($ XhoI $)$ \\
\hline cpn60OERev1 & $\begin{array}{l}\text { GCGGATCCTTAGAACATACCCATACC } \\
(\overline{B a m H I)}\end{array}$ \\
\hline CgroELFwd & GCCATATGGCAAAGCGCATTATTTAC (NdeI) \\
\hline CgroELRev & $\begin{array}{l}\text { GCEGATCCTTAGTAATCGAAGTCACCGCC } \\
(\overline{\text { BamHI })}\end{array}$ \\
\hline
\end{tabular}

${ }^{\star}$ Underlined sequences are cut by the restriction enzyme shown in parentheses. this construct, designated pHR302, was sequenced and the sequence has been submitted to GenBank (accession no. AY328922). The groESL operon from this cyanobacterium was cloned and sequenced previously (Rajaram et al., 2001; accession no. AF324500).

RNA isolation and dot blot hybridization. RNA was isolated from Anabaena cultures as described previously (Rajaram et al., 2001) and treated with DNaseI for removing any DNA contamination. Purified RNA ( $5 \mu \mathrm{g}$ per spot) was spotted onto nylon membranes (Roche Diagnostics), cross-linked with UV and hybridized with specific DIGlabelled DNA probes as described previously (Rajaram et al., 2001).

Generation of antibodies against purified Cpn60 and GroEL proteins of Anabaena L-31. The $1.7 \mathrm{~kb} \mathrm{NdeI/XhoI} \mathrm{fragment} \mathrm{of} \mathrm{the}$ cpn60 gene, amplified from pHR302 using cpn60OEFwd and cpn60OERev primers (Table 1), was cloned at identical sites in the overexpression vector pET29a. The $1.6 \mathrm{~kb} \mathrm{NdeI/BamHI}$ fragment of the groEL gene, amplified from Anabaena L-31 chromosomal DNA using primers CgroELFwd and CgroELRev (Table 1), was cloned at identical sites in the overexpression vector pET16b. The resulting constructs, pETcpn60 and pETgroEL, were transformed into Escherichia coli BL21(pLysS) cells. The Cpn60 and GroEL proteins were overexpressed by induction with $1 \mathrm{mM}$ IPTG at $37^{\circ} \mathrm{C}$ for $1 \mathrm{~h}$ and purified under denaturing conditions ( $8 \mathrm{M}$ urea) using NiNTA affinity chromatography (Qiagen). Purified Cpn60 and GroEL proteins of Anabaena L-31 were used to generate the corresponding polyclonal antibodies in rabbit.

Western blotting and immunodetection. Proteins were extracted, resolved by $10 \%$ linear SDS-PAGE or by $2-D$ IEF/SDS-PAGE and electroblotted onto positively charged nylon membranes (Roche Diagnostics), as described previously (Alahari \& Apte, 1998). Immunodetection was carried out with anti-GroEL antiserum raised against the purified GroEL protein of E. coli (anti-EcGroEL) or with antisera raised against the purified Anabaena L-31 Cpn60 (antiAnCpn60) or GroEL (anti-AnGroEL) proteins, respectively. Cpn60 levels were quantified using a densitometer (Syngene Biotech).

Overexpression of Cpn60 in Anabaena 7120. The cpn60 ORF was PCR-amplified from pHR302 using primers cpn60OEFwd and cpn60OERev1 (Table 1), restriction-digested with NdeI/BamHI and ligated to an identically digested Anabaena 7120 vector pFPN, developed in our laboratory (GenBank accession no. EF468631), to obtain plasmid pFPNcpn. Plasmid pFPN allows integration of the transgene between positions 4654700 and 4655900 in the Anabaena 7120 genome and its expression from a strong light-inducible promoter, PpsbA. Plasmid pFPNcpn was electroporated into Anabaena 7120 as described by Thiel \& Poo (1989) and electrotransformants were selected on BG-11, $\mathrm{N}^{+} \mathrm{NeO}_{25}$ plates.

\section{RESULTS}

\section{Nitrogen-status-dependent effect of heat stress on major metabolic activities in Anabaena L-31}

Anabaena L-31 cells were unable to grow upon continuous exposure to heat stress at $42{ }^{\circ} \mathrm{C}$, irrespective of the nitrogen status of the growth medium (data not shown). At $27{ }^{\circ} \mathrm{C}$, photosynthetic activity was comparable in the presence or absence of combined nitrogen, but decreased to undetectable levels within $15 \mathrm{~h}$ in nitrogen-supplemented $\left(\mathrm{NO}_{3}^{-}\right.$or $\mathrm{NH}_{4}^{+}$) cultures. In comparison, nitrogen-fixing cultures showed very slow inhibition of photosynthesis (Fig. 1a). The nitrate reductase activity, in the absence (L-NR) or 
(a)

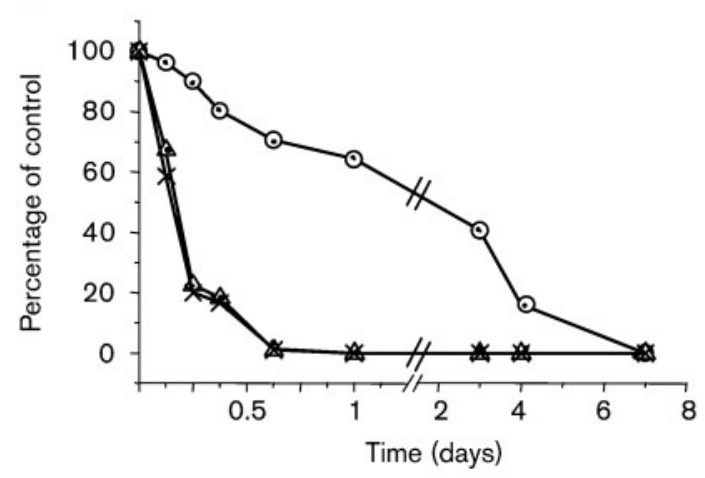

(c)

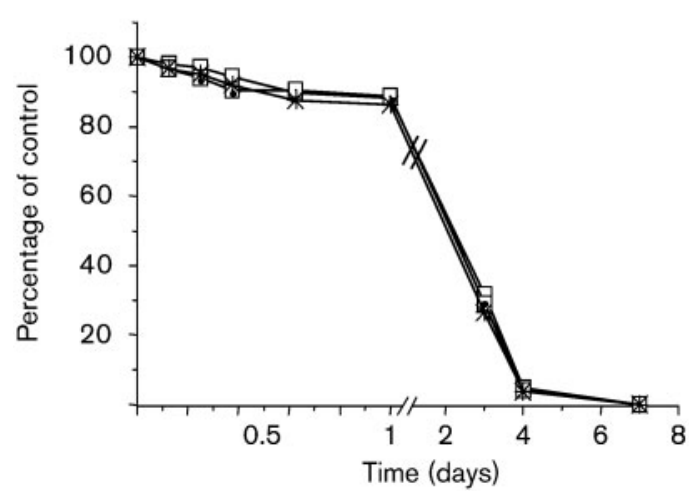

(b)

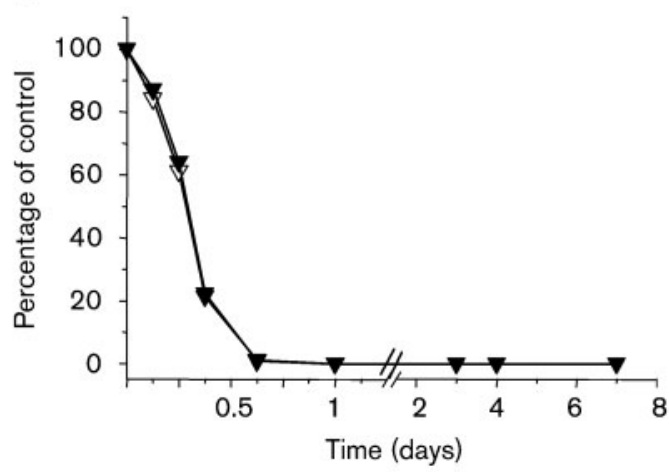

(d)

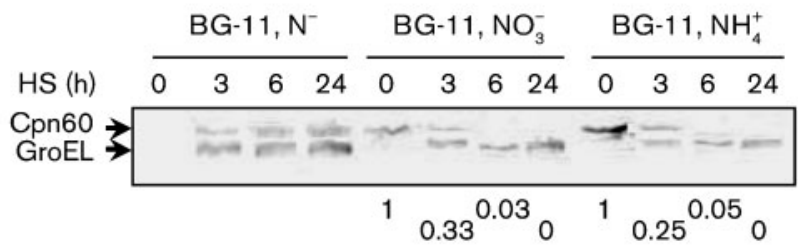

Fig. 1. Effect of heat stress on metabolic activities and Hsp60 synthesis in Anabaena L-31 grown with different combined nitrogen sources. Three-day-old Anabaena L-31 cultures grown under nitrogen-fixing conditions (BG-11, $\mathrm{N}^{-}$) or in the presence of nitrate $\left(\mathrm{BG}-11, \mathrm{NO}_{3}^{-}\right)$or ammonium $\left(\mathrm{BG}-11, \mathrm{NH}_{4}^{+}\right)$were inoculated into the respective fresh media, incubated at 27 or $42{ }^{\circ} \mathrm{C}$ for 7 days and assessed for different physiological activities. (a) Light-dependent photosynthetic $\mathrm{O}_{2}$ evolution. The $100 \%$ photosynthetic activity of controls was $7.267 \pm 0.153 \mu \mathrm{mol} \mathrm{O}_{2}(\mathrm{mg} \mathrm{chl} \mathrm{a})^{-1} \mathrm{~min}^{-1}$ in nitrogen-deficient medium and $7.417 \pm 0.201 \mu \mathrm{mol} \mathrm{O}{ }_{2}(\mathrm{mg} \mathrm{chl} \mathrm{a})^{-1} \mathrm{~min}^{-1}$ and $7.365 \pm 0.172 \mu \mathrm{mol} \mathrm{O}{ }_{2}(\mathrm{mg} \mathrm{chl} \mathrm{a})^{-1} \mathrm{~min}^{-1}$ in the presence of nitrate and ammonium, respectively. $\odot, \mathrm{BG}_{-11}, \mathrm{~N}^{-} ; \Delta, \mathrm{BG}-11, \mathrm{NO}_{3}^{-} ; \times, \mathrm{BG}-11, \mathrm{NH}_{4}^{+}$. (b) Nitrate reductase activity measured in light $(\mathrm{L}-$ $\mathrm{NR}, \nabla)$ or in the presence of $\mathrm{MV}_{\mathrm{r}}-\mathrm{NR}(\boldsymbol{\nabla})$. The $100 \%$ nitrate reductase activity in controls in the absence and presence of $\mathrm{MV}_{\mathrm{r}}-$ $\mathrm{NR}$ was $2.956 \pm 0.58 \mu \mathrm{mol} \mathrm{NO}{ }_{2}^{-}(\mathrm{mg} \mathrm{chl} \mathrm{a})^{-1} \mathrm{~min}^{-1}$ and $3.567 \pm 0.039 \mu \mathrm{mol} \mathrm{NO}{ }_{2}^{-}(\mathrm{mg} \mathrm{chl} \mathrm{a})^{-1} \min ^{-1}$ respectively. (c) Glutamine synthetase activity. The $100 \%$ glutamine synthetase activity of controls was $12.193 \pm 0.092 \mu \mathrm{mol} \gamma$-glutamyl hydroxamate $(\gamma-\mathrm{GH})(\mathrm{mg} \mathrm{chl} \mathrm{a})^{-1} \mathrm{~min}^{-1}$ in nitrogen-deficient medium and $9.645 \pm 0.099 \mu \mathrm{mol} \gamma-\mathrm{GH}\left(\mathrm{mg} \mathrm{chl} \mathrm{a}^{-1} \mathrm{~min}^{-1}\right.$ and $10.325 \pm 0.088 \mu \mathrm{mol} \gamma-\mathrm{GH}(\mathrm{mg} \mathrm{chl} \mathrm{a})^{-1} \mathrm{~min}^{-1}$ in the presence of nitrate and ammonium, respectively. $\square, \mathrm{BG}-11, \mathrm{~N}^{-} ; \square, \mathrm{BG}-$ $11, \mathrm{NO}_{3}^{-} ; *$ BG-11, $\mathrm{NH}_{4}^{+}$(d) Immunodetection of $\mathrm{Hsp} 60$ proteins. Proteins were extracted after a specified duration of heat stress, electrophoretically resolved and electroblotted. Immunodetection was carried out with anti-EcGroEL antisera. Values below the $\mathrm{BG}-11, \mathrm{NO}_{3}^{-}$and $\mathrm{BG}-11, \mathrm{NH}_{4}^{+}$lanes depict $\mathrm{Cpn} 60$ levels during heat stress relative to the respective unstressed controls at $\mathrm{Oh}$.

presence of an artificial reductant $\left(\mathrm{MV}_{\mathrm{r}}-\mathrm{NR}\right)$, similarly decreased to very low levels within $15 \mathrm{~h}$ of heat stress (Fig. 1b). Inhibition of another assimilatory enzyme, glutamine synthetase, was observed only on prolonged exposure to heat stress, but showed no relationship with the nitrogen source in the growth medium (Fig. 1c). Immunodetection techniques showed that a $59 \mathrm{kDa}$ GroEL protein was undetectable at $27^{\circ} \mathrm{C}$, but was strongly induced during heat stress, irrespective of nitrogen status (Fig. 1d). Cpn60 protein was higher in both nitrate or ammonium-supplemented Anabaena cultures compared to nitrogen-fixing cultures, but was undetectable after $6 \mathrm{~h}$ of heat stress in nitrogen-supplemented cultures, unlike its accumulation in nitrogen-deficient cultures (Fig. 1d).

\section{Effect of nitrogen status on expression of hsp60 genes}

Detailed analysis of $h s p 60$ expression in nitrogen-deficient $\left(\mathrm{BG}-11, \mathrm{~N}^{-}\right.$) and nitrate-supplemented (BG-11, $\mathrm{NO}_{3}^{-}$) cultures confirmed the results shown in Fig. 1(d). The identities of the $59 \mathrm{kDa}$ (GroEL) and $61 \mathrm{kDa}$ (Cpn60) Hsp60 proteins were confirmed by 2 -D electrophoretic resolution (Fig. 2a) and MALDI-TOF-MS-based peptide 
(a)

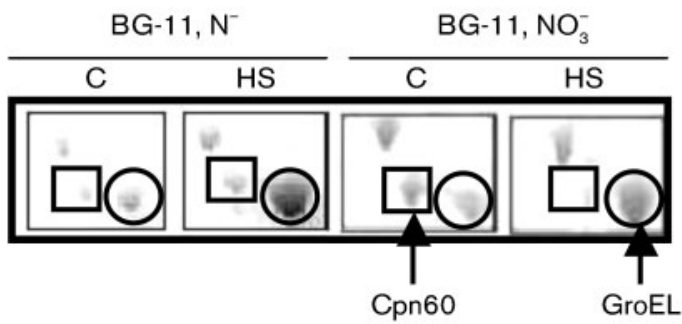

(b)

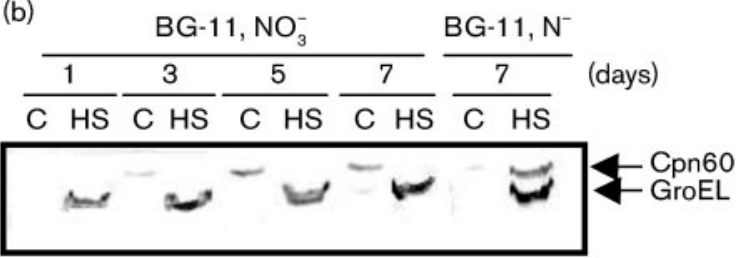

(d)

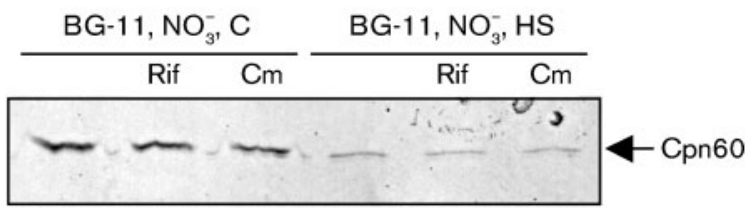

Fig. 2. Expression of $h s p 60$ genes in heat-stressed Anabaena L-31 in the presence or absence of combined nitrogen. (a) Identification of $\mathrm{Hsp} 60$ proteins. Proteins were extracted after $24 \mathrm{~h}$ incubation at $27{ }^{\circ} \mathrm{C}$ (control, $\mathrm{C}$ ) or $42{ }^{\circ} \mathrm{C}$ (heat stress, $\mathrm{HS}$ ), separated by 2-D IEF/SDS-PAGE and stained with Coomassie brilliant blue. The marked spots were identified by peptide mass fingerprinting. (b) Immunodetection of $\mathrm{Hsp} 60$ proteins. Three-day-old Anabaena L-31 cultures grown in BG-11, N ${ }^{+}$medium were exposed to heat stress $\left(42{ }^{\circ} \mathrm{C}\right)$ for 7 days. Hsp60 levels detected with anti-EcGroEL antiserum were compared with those in BG-11, $\mathrm{N}^{-}$cultures heat-stressed for 7 days. Other details were as described in the legend to Fig. 1(d). (c) Detection of cpn60 transcript. Three-day-old Anabaena L-31 cells grown in the presence or absence of nitrate were subjected to heat stress for $1 \mathrm{~h}$. Equal amounts of RNA ( $5 \mu \mathrm{g}$ per spot) isolated from control (C) and heat-stressed (HS) cultures were blotted onto nylon membrane and hybridized with a cpn60 gene probe. A 16S rDNA probe was used as internal control. (d) Effect of transcriptional and translational inhibitors on Cpn60 levels. Rifampicin (Rif, $50 \mu \mathrm{g} \mathrm{ml}^{-1}$ ) or chloramphenicol $\left(\mathrm{Cm}, 34 \mu \mathrm{g} \mathrm{m}{ }^{-1}\right)$ were added to 3-day-old Anabaena L-31 cells grown in $\mathrm{BG}-11, \mathrm{NO}_{3}^{-}$and subsequently cultures were grown either at $27{ }^{\circ} \mathrm{C}$ (C) or subjected to heat stress at $42{ }^{\circ} \mathrm{C}(\mathrm{HS})$ for $3 \mathrm{~h}$. Cpn60 protein was immunodetected from the specified cell extracts using anti-AnCpn60 antisera.

mass fingerprinting analysis (data not shown). The absence of Cpn60 protein during prolonged heat stress in the presence of combined nitrogen (Fig. 2b) correlated well with the rapid inactivation of photosynthetic machinery and nitrate reduction observed previously (Fig. 1a, b). Heat stress strongly and rapidly repressed the transcription of the cpn60 gene (Fig. 2c), and also caused degradation of the pre-synthesized $61 \mathrm{kDa}$ Cpn60 protein (Fig. 2a, b) during nitrate-supplemented growth. In comparison, cpn60 transcription was significantly enhanced by heat stress in nitrogen-fixing cultures (Fig. 2c). Preincubation of nitrategrown cultures with transcriptional (rifampicin) or translational (chloramphenicol) inhibitors showed that Cpn60 protein was quite stable in controls up to $3 \mathrm{~h}$, but was rapidly degraded during heat stress (Fig. 2d).

\section{Effect of nitrogen status on the recovery of Anabaena L-31 cells from heat stress}

Previous studies showed that nitrogen-fixing cultures of Anabaena L-31 were capable of a remarkable recovery even after 7 days of continuous heat stress at $42{ }^{\circ} \mathrm{C}$ (Rajaram \& Apte, 2003). When compared to their respective controls, the recovery of nitrogen-fixing cultures was relatively more rapid than that of the nitrate-grown cultures (Fig. 3a), as would be expected if Cpn60 was essential for nitratesupplemented growth and metabolism. Rapid recovery of photosynthetic activity in the heat-stressed nitrogen-fixing cultures (Fig. 3b) did not transform into equivalent growth recovery (Fig. 3a), since nitrogenase activity takes much longer to recover under such conditions (Rajaram \& Apte, 2003). Recovery of nitrate reductase (L-NR) activity followed kinetics very similar to that of recovery of photosynthetic activity in nitrate-grown cultures (Fig. 3b).

The correlation between Cpn60 levels, photosynthesis and nitrate reduction was carefully monitored during recovery of nitrogen-supplemented cultures from a short-term ( 1 day) heat stress (Fig. 4). About $25 \%$ of the Cpn60 protein was synthesized by $2 \mathrm{~h}$ of recovery (Fig. $4 \mathrm{a}$ ) and measurable recovery of photosynthetic and nitrate reductase $\left(\mathrm{MV}_{\mathrm{r}}-\mathrm{NR}\right)$ activities commenced subsequently (Fig. 4b). Thus the presence of a threshold level of Cpn60 may be a prerequisite for restoration of photosynthesis and nitrate assimilation in nitrate-supplemented cultures following heat stress. 

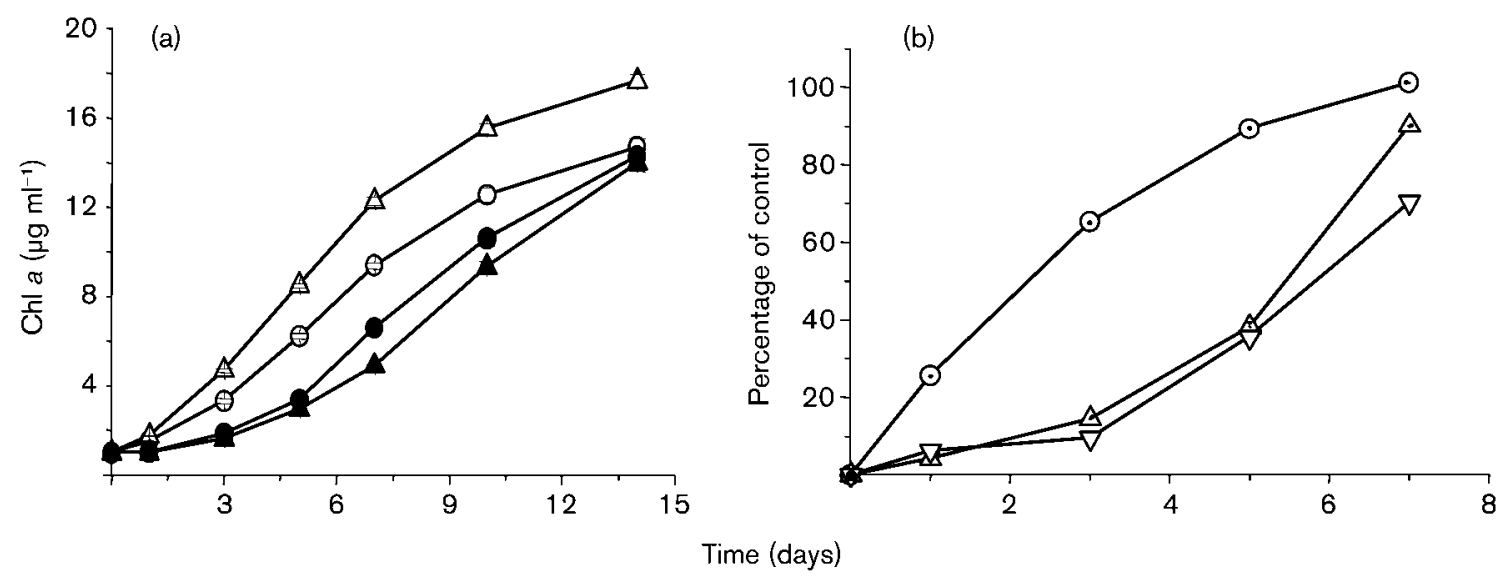

Fig. 3. Effect of nitrogen status on the recovery of 7 day heat-stressed Anabaena L-31. Cultures were grown either in the absence $\left(\mathrm{BG}-11, \mathrm{~N}^{-}\right.$) or presence $\left(\mathrm{BG}-11, \mathrm{NO}_{3}^{-}\right.$) of nitrate in the medium and incubated either at $27^{\circ} \mathrm{C}$ (control, $\mathrm{C}$ ) or at $42{ }^{\circ} \mathrm{C}$ (heat stress, HS) for 7 days. The cells were then washed, inoculated in the respective fresh media and allowed to recover at $27^{\circ} \mathrm{C}$. (a) Growth recovery in terms of chl a content of heat-stressed cultures was compared with their respective unstressed control for 14 days. $\bigcirc$, BG-11, $\mathrm{N}^{-}, \mathrm{C}$; $\bullet$, BG-11, $\mathrm{N}^{-}, \mathrm{HS} ; \triangle, \mathrm{BG}-11, \mathrm{NO}_{3}^{-}, \mathrm{C} ; \mathbf{\Delta}, \mathrm{BG}-11, \mathrm{NO}_{3}^{-}, \mathrm{HS}$. (b) Recovery of light-dependent photosynthetic $\mathrm{O}_{2}$ evolution (BG-11, $\mathrm{N}^{-}, \mathrm{PS}, \odot$ ) for nitrogen-fixing cultures, and photosynthetic (BG-11, $\left.\mathrm{NO}_{3}^{-}, \mathrm{PS}, \Delta\right)$ and nitrate reductase (BG-11, $\left.\mathrm{NO}_{3}^{-}, \mathrm{L}-\mathrm{NR}, \nabla\right)$ activities for nitrate-supplemented cultures. Other details were as given in the legend to Fig. 1.

\section{Overexpression of Cpn60 in Anabaena 7120}

Attempts were made to overexpress Cpn60 in Anabaena. Since Anabaena L-31, is not amenable to genetic manipulation, such attempts were made in Anabaena 7120, which shows an Hsp60 expression profile similar to that in Anabaena L-31 (Figs 1d and 5a). For this, plasmid pFPNcpn was introduced into Anabaena 7120 by electrotransformation. Immunodetection with anti-AnCpn60 antiserum confirmed 2.4-fold overexpression of Cpn60 protein in recombinant Anabaena 7120 cells (hereafter referred to as AnFPNcpn) (lane C, Fig. 5b) compared to Anabaena 7120 (lane C, Fig. 5a). Significantly higher levels of Cpn60 were observed in nitrate-grown AnFPNcpn cultures after 3 days of heat stress (Fig. 5b), unlike in Anabaena 7120 (Fig. 5a), and decreased thereafter (Fig. 5b). As expected, the GroEL levels remained similarly enhanced during heat stress in both cultures (Fig. $5 a, b$ ).

\section{Effect of overexpression of Cpn60 on metabolic activities in Anabaena $\mathbf{7 1 2 0}$}

The AnFPNcpn cultures grew slowly at $42{ }^{\circ} \mathrm{C}$, unlike Anabaena 7120 which failed to grow (Fig. 6a). Correspondingly, the photosynthetic and nitrate reductase activities in AnFPNcpn cultures showed superior thermal stability, while glutamine synthetase activity was not significantly affected by Cpn60 overexpression (Fig. 6bd). While 1 day of heat stress completely abolished both photosynthetic and nitrate reductase activities in Anabaena 7120 (Fig. 6b, c), AnFPNcpn cultures retained over 80$90 \%$ and $30-50 \%$ of their activities on day 1 and day 3 , respectively, under the same conditions. The sustenance of photosynthetic and nitrate reductase activities in the transformed cells during heat stress (Fig. 6b, c) closely corresponded with maintenance of higher levels of Cpn60 (Fig. 5b).

The AnFPNcpn cells also showed faster recovery than the wild-type Anabaena 7120 cells when exposed to 1 day of heat stress (Fig. 6e). After 4 days of heat stress the difference in recovery was less impressive (Fig. 6f). This correlated well with much higher levels of Cpn60 in AnFPNcpn, compared to Anabaena 7120, after 1 day of heat stress than after 4 days (Fig. 5a, b).

\section{DISCUSSION}

Information available from genome sequences (www.kazusa.or.jp/cyano) and the limited heat-shock response studies in cyanobacteria have revealed the presence of two hsp60 genes, the groESL operon and the cpn60 gene, in all of them. Both genes have been cloned and sequenced from the nitrogen-fixing cyanobacterium Anabaena sp. strain L-31 by our laboratory (GenBank AF324500 and AY328922). In the unicellular adiazotrophic cyanobacterium Synechocystis sp. PCC6803, the two hsp60 genes show differential expression in response to heat stress and lightdark cycles (Asadulghani et al., 2003; Glatz et al., 1997; Kovacs et al., 2001; Mary et al., 2004) as well as photosynthetic electron transport (Glatz et al., 1997), or during exposure to UV or oxidative stress (Chitnis \& Nelson, 1991). Functional differences in the two Hsp60 proteins have been observed in the complementation of the 
(a)
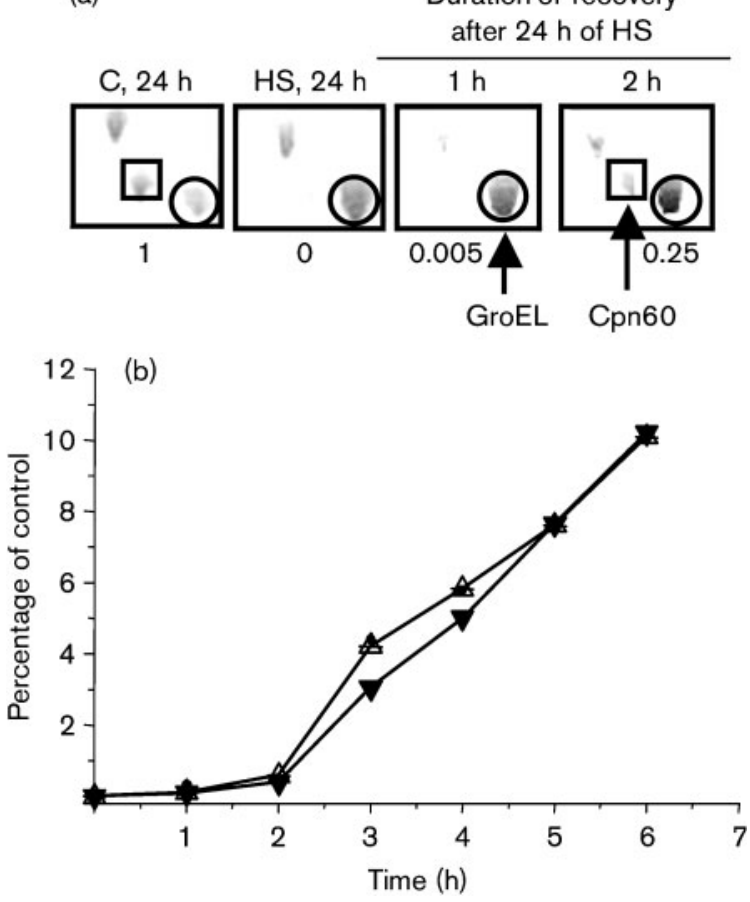

Fig. 4. Recovery of short-term heat-stressed nitrate-supplemented Anabaena L-31. Cells heat-stressed (HS) at $42{ }^{\circ} \mathrm{C}$ for $24 \mathrm{~h}$ were washed and allowed to recover in fresh BG-11, $\mathrm{N}^{+}$at $27^{\circ} \mathrm{C}$ (C) for $6 \mathrm{~h}$. (a) Hsps resolved by 2-D IEF/SDS-PAGE and immunodetected with anti-EcGroEL antisera. Values below the boxes depict the levels of Cpn60 relative to that in C, $24 \mathrm{~h}$. (b) Photosynthetic (PS, $\Delta$ ) and $\mathrm{MV}_{\mathrm{r}}-\mathrm{NR}(\boldsymbol{\nabla})$ activities were measured and expressed as a percentage of the unstressed control. Other details were as described in the legend to Fig. 1.

E. coli groEL44 mutant by the groESL operon and cpn60 gene of Synechocystis sp. PCC6803 (Kovacs et al., 2001), but their individual roles have remained enigmatic.

Photosynthesis is inactivated during heat stress in cyanobacteria (Eriksson \& Clarke, 1996) and the Hsp60 proteins have been found to be associated with carboxysomes (Jager \& Bergman, 1990). In Synechocystis sp. PCC6803, the cpn60 gene is not transcribed during heat stress in the dark nor in the presence of DCMU [3-(3,4-dichlorophenyl)-1, 1-dimethylurea] (Glatz et al., 1997), suggesting that it may be required for the assembly of multimeric photosynthetic complexes in light. The non-availability of the Cpn60 protein in nitrogen-supplemented Anabaena cultures during heat stress may thus be responsible for the faster inactivation of photosynthesis compared to that observed under nitrogen-fixing conditions (Figs 1, 2, 5 and 6). Overexpression of Cpn60 does confer a higher thermostability of photosynthesis to Anabaena (Fig. 6).

This study is the first in which nitrogen-status-dependent regulation of the $h s p 60$ genes has been studied. Combined nitrogen-supplemented unstressed Anabaena cultures (a)

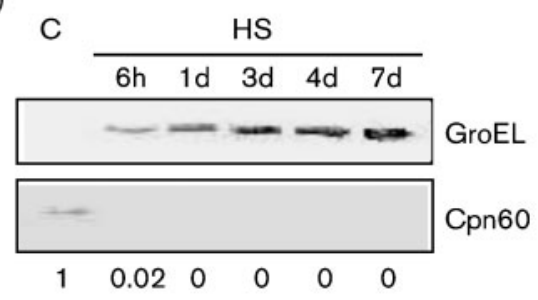

(b)

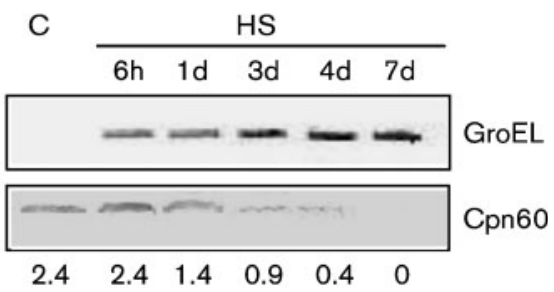

Fig. 5. Levels of Hsp60 proteins in heat-stressed nitratesupplemented Anabaena 7120 and AnFPNcpn cultures. Immunodetection of GroEL and Cpn60 proteins, using specific anti-AnGroEL and anti-AnCpn60 antisera, respectively, in control (C) and heat-stressed (HS) Anabaena 7120 (a) and AnFPNcpn (b) cultures. Values below the lanes depict $\mathrm{Cpn60}$ levels relative to the Anabaena 7120 unstressed control (a, lane C). Other details were as described in the legend to Fig. 2.

exhibit significantly higher levels of Cpn60 compared to nitrogen-fixing cultures. This is perhaps indicative of a higher requirement of Cpn60 for photosynthesis and/or nitrate reductase. Both Hsp60 proteins accumulate during prolonged exposure to heat stress under nitrogen-fixing conditions with GroEL being more strongly induced by heat stress than Cpn60 (Fig. 2; Rajaram \& Apte, 2003). Novel features elucidated by the present study are (i) the repression of cpn60 expression and degradation of Cpn60 by heat stress selectively during nitrogen-supplemented growth of Anabaena (Fig. 2) and (ii) apparent correlation between the Cpn60 levels and photosynthetic and nitrate reductase activities (Figs 1, 4, 5 and 6). The data presented clearly show that in nitrogen-supplemented cultures, Cpn60 levels during heat stress are determined by inhibition of transcription (Fig. 2c) and enhanced degradation of the Cpn60 protein (Fig. 2a, b and d). Cpn60 is stable in nitrogen-supplemented cultures grown at $27{ }^{\circ} \mathrm{C}$ (Fig. 2d). Using a pulse-chase technique, we have shown previously that the Cpn60 protein is stable up to $24 \mathrm{~h}$ of heat stress under nitrogen-fixing conditions (Rajaram \& Apte, 2003). The instability during heat stress in nitrogen-supplemented cultures may, therefore, be due to specific proteolytic degradation of the protein.

In cyanobacteria, photosynthesis and nitrate reduction are closely related, since nitrate reductase requires a photoreduced ferredoxin (Flores et al., 2005). However, nitrate reductase activity was inhibited during heat stress, even when provided with an artificial reductant, $M_{\mathrm{r}}-\mathrm{NR}$, 
(a)

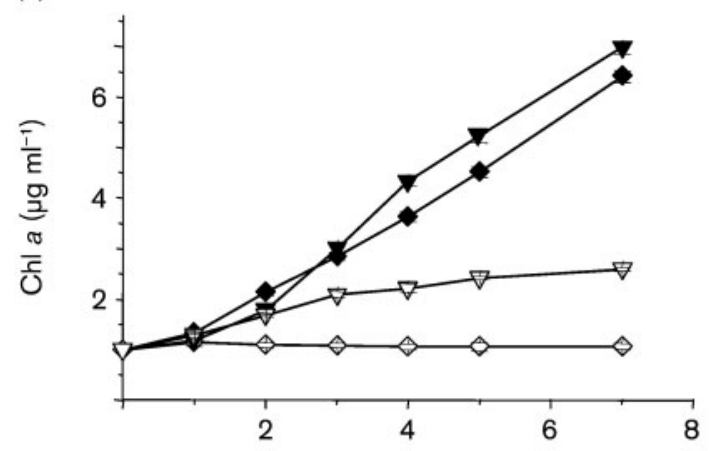

(b)

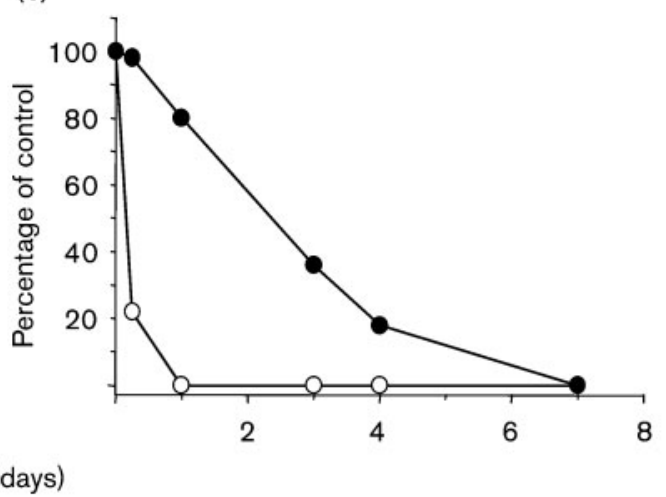

(c)

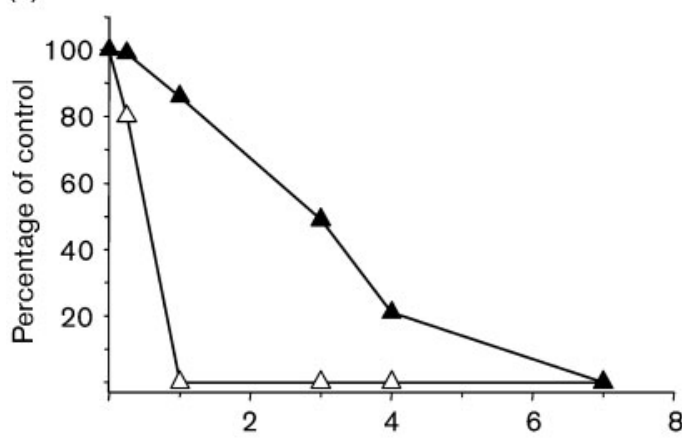

(d)

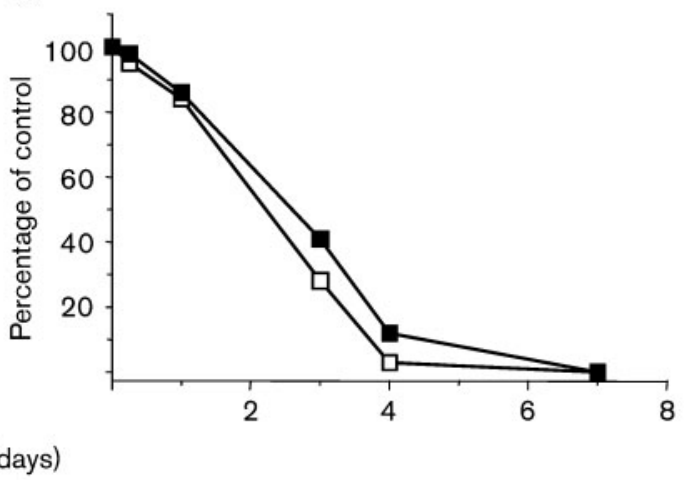

(e)

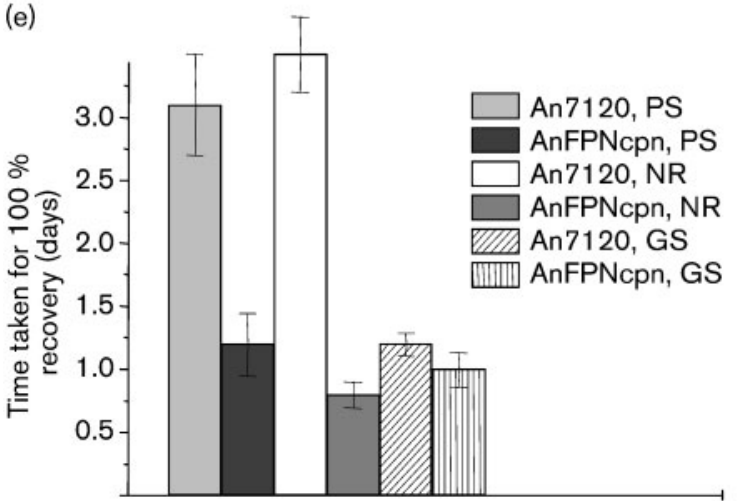

(f)

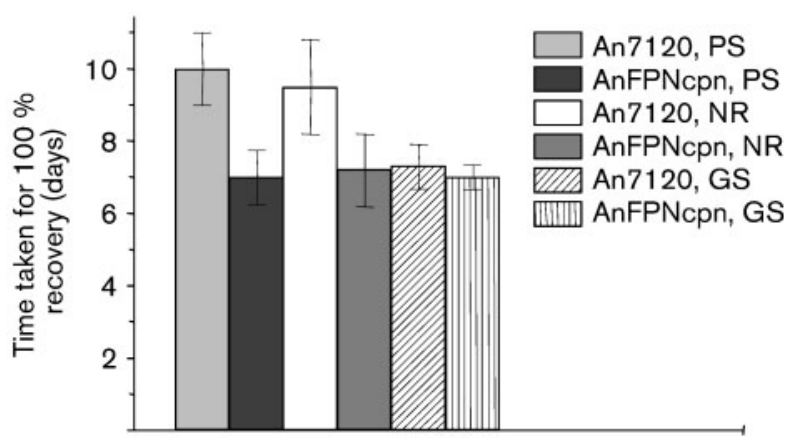

Fig. 6. Comparative analysis of photosynthetic, nitrate reductase and glutamine synthetase activities in Anabaena 7120 and AnFPNcpn during heat stress and recovery therefrom. (a-d) Three-day-old nitrate-grown Anabaena 7120 and AnFPNcpn cultures were subjected to heat stress at $42{ }^{\circ} \mathrm{C}$ and analysed for (a) growth, (b) photosynthetic, (c) nitrate reductase and (d) glutamine synthetase activities. (e, f) Recovery of photosynthetic (PS), nitrate reductase (NR) and glutamine synthetase (GS) activities of nitrate-grown Anabaena 7120 and AnFPNcpn cultures, heat-stressed for (e) 1 day and (f) 4 days compared with respective controls. The $100 \%$ control photosynthetic activity was $7.432 \pm 0.189 \mu \mathrm{mol} \mathrm{O} 2(\mathrm{mg} \mathrm{chl} \mathrm{a})^{-1} \mathrm{~min}^{-1}$ for Anabaena 7120 and $7.565 \pm 0.215 \mu \mathrm{mol} \mathrm{O}_{2}(\mathrm{mg} \mathrm{chl} \mathrm{a})^{-1} \mathrm{~min}^{-1}$ for AnFPNcpn cultures. The $100 \%$ control nitrate reductase activity $\left(\mathrm{MV}_{\mathrm{r}^{-}}\right.$ $\mathrm{NR}$ ) was $3.569 \pm 0.041 \mu \mathrm{mol} \mathrm{NO}_{2}^{-}\left(\mathrm{mg} \mathrm{chl} \mathrm{a}^{-1} \mathrm{~min}^{-1}\right.$ for Anabaena 7120 and $3.728 \pm 0.065 \mu \mathrm{mol} \mathrm{NO}_{2}^{-}\left(\mathrm{mg} \mathrm{chl} \mathrm{a}^{-1} \mathrm{~min}^{-1}\right.$ for AnFPNcpn cultures. The $100 \%$ control glutamine synthetase activity was $10.471 \pm 0.195 \mu \mathrm{mol} \gamma-\mathrm{GH}\left(\mathrm{mg} \mathrm{chl} \mathrm{a}^{-1} \mathrm{~min}^{-1} \mathrm{for}\right.$ Anabaena 7120 and $13.172 \pm 0.136 \mu \mathrm{mol} \gamma-\mathrm{GH}(\mathrm{mg} \mathrm{chl} \mathrm{a})^{-1} \mathrm{~min}^{-1}$ for AnFPNcpn cultures. (a) $>, 7120 \mathrm{C} ; \square, 7120 \mathrm{HS} ; \mathbf{\nabla}$, AnFPNcpn C; $\nabla$, AnFPNcpn HS. (b) $\bigcirc$, Anabaena 7120; •, AnFPNcpn. (c) $\triangle$, Anabaena 7120; $\mathbf{\Delta}$, AnFPNcpn. (d) $\square$, Anabaena 7120; $\mathbf{0}$, AnFPNcpn.

indicating that heat stress influenced nitrate reductase and photosynthesis independently. Thermal inactivation of nitrate reductase has been reported in yeast (Siverio et al., 1993). Interestingly, loss or overexpression of Cpn60 did not directly influence glutamine synthetase activity in Anabaena (Figs 1 and 6). In E. coli, GroES and GroEL are 
reportedly required for the assembly of glutamine synthetase (Fisher, 1994). The decrease in glutamine synthetase activity on prolonged exposure to heat stress in Anabaena may be a generic effect of heat stress, which causes denaturation and repression of synthesis of several proteins.

The higher thermosensitivity of nitrate-supplemented Anabaena cultures may be due to complete loss of two vital assimilatory processes (Fig. 1) in the absence of Cpn60 (Fig. 2), compared to that of only nitrogen fixation in heatstressed nitrogen-fixing cultures. The rapid recovery of heat-stressed diazotrophic cultures may be due to the accumulation of both GroEL and Cpn60 chaperonins in them, while the absence of Cpn60 in heat-stressed nitratesupplemented cultures seems to limit their recovery until adequate Cpn60 is resynthesized. Our attempts to mutagenize cpn60 did not yield viable mutants (data not shown), but this clearly showed that the cpn60 gene is essential for normal growth of Anabaena. The overexpression of the Cpn60 protein in Anabaena 7120 (Fig. 5), on the other hand, resulted in superior thermal stability of both photosynthesis and nitrate reduction compared to the wild-type strain (Fig. 6). The Cpn60 chaperonin thus appears to play a major role in cellular metabolism, especially during nitrogen-supplemented growth of Anabaena.

\section{ACKNOWLEDGEMENTS}

We thank Professor Koreaki Ito, Institute for Virus Research, Kyoto University, Japan, for providing the anti-GroEL antiserum, and Akhilesh Chaurasia in our laboratory for the integrative expression vector pFPN and electrotransformation of Anabaena.

\section{REFERENCES}

Alahari, A. \& Apte, S. K. (1998). Pleiotropic effects of potassium deficiency in a heterocystous, nitrogen-fixing cyanobacterium Anabaena torulosa. Microbiology 144, 1557-1563.

Apte, S. K. \& Haselkorn, R. (1990). Cloning of salinity stress-induced genes from the salt tolerant nitrogen-fixing cyanobacterium Anabaena torulosa. Plant Mol Biol 15, 723-733.

Apte, S. K., Fernandes, T., Badran, H. \& Ballal, A. (1998). Expression and possible role of stress-responsive proteins in Anabaena. J Biosci 23, 399-406.

Asadulghani, Suzuki, Y. \& Nakamoto, H. (2003). Light plays a key role in the modulation of heat shock response in the cyanobacterium Synechocystis sp. PCC 6803. Biochem Biophys Res Commun 306, 872-879.

Bhagwat, A. A. \& Apte, S. K. (1989). Comparative analysis of proteins induced by heat shock, salinity, and osmotic stress in the nitrogenfixing cyanobacterium Anabaena sp. strain L-31. J Bacteriol 171, 5187-5189.

Castenholz, R. W. (1988). Culturing methods for cyanobacteria. Methods Enzymol 167, 68-93.

Chitnis, P. R. \& Nelson, N. (1991). Molecular cloning of the genes encoding two chaperone proteins of the cyanobacterium Synechocystis sp. PCC 6803. J Biol Chem 266, 58-65.
Eriksson, M. J. \& Clarke, A. K. (1996). The heat shock protein ClpB mediates the development of thermotolerance in the cyanobacterium Synechococcus sp. strain PCC 7942. J Bacteriol 178, 4839-4846.

Fischer, H. M., Babst, M., Kaspar, T., Acuna, G., Arigoni, F. \& Hennecke, H. (1993). One member of a groESL-like chaperonin multigene family in Bradyrhizobium japonicum is co-regulated with symbiotic nitrogen fixation genes. EMBO J 12, 2901-2912.

Fisher, M. T. (1994). The effect of GroES on the GroEL-dependent assembly of dodecameric glutamine synthetase in the presence of ATP and ADP. J Biol Chem 269, 13629-13636.

Flores, E., Frias, J. E., Rubio, L. M. \& Herrero, A. (2005). Photosynthetic nitrate assimilation in cyanobacteria. Photosynth Res 83, 117-133.

Glatz, A., Horvath, I., Varvasovszki, V., Kovacs, E., Torok, Z. \& Vigh, L. (1997). Chaperonin genes of the Synechocystis PCC 6803 are differentially regulated under light-dark transition during heat stress. Biochem Biophys Res Commun 239, 291-297.

Guglielmi, G., Mazodier, P., Thompson, C. J. \& Davies, J. (1991). A survey of the heat shock response in four Streptomyces species reveals two groEL-like genes and three GroEL-like proteins in Streptomyces albus. J Bacteriol 173, 7374-7381.

Hageman, R. H. \& Hucklesby, D. P. (1971). Nitrate reductase in higher plants. Methods Enzymol 23, 491-503.

Herrero, A., Flores, E. \& Guerrero, M. G. (1981). Regulation of the nitrate reductase levels in the cyanobacteria, Anacystis nidulans, Anabaena sp. strain 7119 and Nostoc sp. strain 6719. J Bacteriol 145, $175-180$.

Jager, K. M. \& Bergman, B. (1990). Localization of a multifunctional chaperonin (GroEL protein) in nitrogen-fixing Anabaena PCC 7120. Planta 183, 120-125.

Kovacs, E., van der Vies, S. M., Glatz, A., Torok, Z., Varvasovszki, V., Horvath, I. \& Vigh, L. (2001). The chaperonins of Synechocystis PCC 6803 differ in heat inducibility and chaperone activity. Biochem Biophys Res Commun 289, 908-915.

Lehel, C., Los, D., Wada, H., Gyorgei, J., Horvath, I., Kovacs, E., Murata, N. \& Vigh, L. (1993). A second groEL-like gene, organized in a groESL operon is present in the genome of Synechocystis sp. PCC 6803. J Biol Chem 268, 1799-1804.

Mackinney, G. (1941). Absorption of light by chlorophyll solutions. J Biol Chem 140, 315-322.

Martin, G., Hachnel, W. \& Bager, P. (1997). Oxidative inactivation of glutamine synthetase from the cyanobacterium Anabaena variabilis. J Bacteriol 179, 730-734.

Mary, I., Tu, C.-J., Grossman, A. \& Vaulot, D. (2004). Effects of high light on transcripts of stress-associated genes for the cyanobacteria Synechocystis sp. PCC 6803 and Prochlorococcus MED4 and MIT9313. Microbiology 150, 1271-1281.

Morimoto, R. I., Jurivich, D. A., Kroeger, P. E., Mathur, S. K., Murphy, S. P., Nakai, A., Sarge, K., Abravaya, K. \& Sistonen, L. T. (1994). Regulation of heat shock gene transcription by a family of heat shock factors. In The Biology of Heat Shock Proteins and Molecular Chaperones, pp. 417-455. Edited by R. I. Morimoto, A. Tessiers \& C. Georgopoulos. Cold Spring Harbor, NY: Cold Spring Harbor Laboratory.

Rajaram, H. \& Apte, S. K. (2003). Heat-shock response and its contribution to thermotolerance of the nitrogen-fixing cyanobacterium Anabaena sp. strain L-31. Arch Microbiol 179, 423-429.

Rajaram, H., Ballal, A. D., Apte, S. K., Wiegert, T. \& Schumann, W. (2001). Cloning and characterization of the major groESL operon from a nitrogen-fixing cyanobacterium Anabaena sp. strain L-31. Biochim Biophys Acta 1519, 143-146. 
Rinke de Wit, T. F., Bekelie, S., Osland, A., Miko, T. L., Hermans, P. W., van Soolingen, D., Drijfhout, J. W., Schoningh, R., Janson, A. A. \& Thole, J. E. (1992). Mycobacteria contain two groEL genes: the $2^{\text {nd }}$ Mycobacterium leprae groEL gene is arranged in an operon with groES. Mol Microbiol 6, 1995-2007.

Rusanganwa, E. \& Gupta, R. S. (1993). Cloning and characterization of multiple GroEL chaperonin encoding genes in Rhizobium melioti. Gene 126, 67-75.

Siverio, J. M., Gonzalez, C., Mendoza-Riquel, A., Perez, M. D. \& Gonzalez, G. (1993). Reversible inactivation and binding to mitochondria of nitrate reductase by heat shock in the yeast Hansenula anomala. FEBS Lett 318, 153-156.
Thiel, T. \& Poo, H. (1989). Transformation of a filamentous cyanobacterium by electroporation. J Bacteriol 171, 5743-5746.

Thomas, J. (1970). Absence of the pigments of photosystem II of photosynthesis in heterocysts of a blue-green alga. Nature 228, 181-183.

Yura, T., Kanemori, M. \& Morita, M. T. (2000). The heat shock response: regulation and function. In Bacterial Stress Responses, pp. 318. Edited by G. Storz \& R. Hengge-Aronis. Washington, DC: American Society for Microbiology.

Edited by: K. Forchhammer 